\title{
IMPLEMENTATION PROGRAME EVALUATION OF SOCIAL HEALTH SERVICE IN HEALTH INSURANCE BY FAMILY DOCTOR IN PONTIANAK
}

\author{
Imran \\ Tanjungpura University of Pontianak \\ imranpontianak@yahoo.com
}

\begin{abstract}
The purpose of the research was to evaluate the implementation of health service process, participant of social health insurance by family doctor, that consist of necessary, the background of the program, readiness of the program, realization of the program and the accomplishment of the health service program in health insurance by family doctor. The research used qualitative and quantitative approach by CIPP (Context, Input, Process, Product) evaluation model. The participants of social health insurance program by family doctor were 10.487 people. Most of them gave positive response and the satisfaction index of health service by family doctor was good. The result of the research showed the implementation of health service in health insurance by family doctor have done with the appropriate purpose and standard. The result of this evaluation research was the health service in health insurance program by family doctor could increase the participants of health insurance's health level in Pontianak City and it can be continued by The Social Health Insurance Provider.
\end{abstract}

Keywords: Social health insurance, family doctor, health service program, health level.

Health is a fundamental right of every citizen. Therefore every individual, family, and society is entitled to health protection. To realize the mandate of the Constitution, Article 14 of the Law on Health affirms that the state is responsible for planning, organizing, organizing, fostering and supervising public health services to the public in order to fulfill the right to healthy living for its citizens, including the poor and needy.

As stated in the Health Act no. 36 of 2009 that health development aims to increase awareness, willingness and ability to live healthy for every person to realize the optimal health status of society. To realize these objectives the government has sought with various programs, one of which is with the National Social Security System program. To succeed the program the government in cooperation with Limited Company of Health insurance in the delivery of health services. There are several health service providers who have been joining to succeed the government program. Community health center is an organizational unit that belongs to Limited Company of Health insurance in providing health services to the public including health insurance participants. For firstdegree outpatient services for participants Social health insurance is generally implemented in community health centers. Doctors Public health centers as the spearhead of health services have a high non-medical workload, this resulted in most of the time the doctor's health center was consumed by activities outside the community health center so that treatment services in public health centers are generally not given directly by the doctor but by paramedics. This is one of the factors causing dissatisfaction of health insurance participants in obtaining the first outpatient service, which is seen from the low utilization of public health center by the participants only $36.9 \%$ of the participants in need. (Limited Company of Indonesia Health Insurance, 2003).

To anticipate the above problems, one of the efforts developed is by expanding the first level outpatient network for the participants of health insurance through family doctor services in addition to public health center. From the evaluation of this program, it was found that the great benefit from the aspect of service quality and cost control so it is feasible to be developed in other areas. 
Any change in the payment mechanism from the form of fee for service to the form of the prospective payment system, among others, through the capitation system (prepaid) still keeps some questions, such as whether the change of form of payment can lead to efficiency without sacrificing the quality of service and whether the change is also profitable the health care provider in this case the family doctor. This is noteworthy because the satisfaction of health providers can also affect the quality in providing health services, (Limited Company of Indonesia Health Insurance, 2003) According to Djoko Wijono patient satisfaction is influenced by the quality of service which includes: direct evidence, reliability, responsiveness, comfort and attention. Based on some of the above phenomenon, the researchers want to reveal the problem by raising the title Implementation of Health Service Program Social Health Insurance by Family Doctor in Pontianak City (Study Evaluation Model CIPP).

The benefits of a policy evaluation are, to examine the consequences of a policy or in other words according to Danim to seek answers to what happens as a result of policy implementation. In addition, the policy impact is intended to examine the consequences of implementing a policy and to discuss "the relationship between the means used and the outcomes to be achieved". The public policy analysis methodology essentially incorporates five common procedures commonly used in human problem solving: definition (problem formulation), prediction (forecasting), prescriptions (recommendations), and evaluations that have names similar to those used in everyday language that function provide information on the value or usefulness of the problem-solving or problem-solving consequences. based on the policy evaluation process that the researcher has disclosed above, it can be done the comparison between program policy criteria that have been established with the process of implementing the program that has been implemented, so that the researcher wants to get the result about the implementation of Health Service program of social health insurance by family doctor which has been implemented with process, defined criteria. Health care program Family health insurance is one of the Ministry of Health's programs as an effort to improve public health service system and increase the health status of society optimally.

The purpose of the health care social health insurance program by family doctors is as according to Health Act No. 36 of 2009 , that health is fundamental to every citizen. Therefore, every individual, family and society are entitled to health protection.

The evaluation model of program policies with evaluation systems is mostly done using a logical framework approach which is an analytical tool for planners or managers in conducting situational analysis in the preparation stage of the program, establishing a logical hierarchy of objectives to be achieved, identifying potential the risk of achieving sustainable goals and outcomes, establishes a way for project outputs and outcomes to be properly monitored and evaluated, present project summary in standard format, and monitor and review program implementation. In other words, evaluation includes problem analysis, stakeholder analysis, development of a logical hierarchy of objectives, possible risk identification, and selection of adopted implementation strategies. In general, the conceptual evaluation framework consists of four main elements, namely: Context, Input, Process and Product. In this research, the researcher chose CIPP approach model, context, input, process, product, so this model of choice is very appropriate to evaluate health service program of social health insurance by family doctor.

The CIPP model evaluation study, developed by Stufflebeam, that evaluation is the process of obtaining and presenting useful information for considering decision-making alternatives.

This research uses descriptive method with qualitative and quantitative approach, both in data recording process and for dissemination of research result on all samples (Health Insurance participants) about to be evaluated that is by using interview, observation, field note and required documents, then presented in a narrative form in accordance with the circumstances that occur. This evaluation study is directed to the components achieved in the implementation of Health Insurance 
health service program by family doctors. Further data collected will be analyzed (from data in the form of evaluation of context, input, process and product). This will be a benchmark for the success of the health service implementation program Family health insurance family physician.

\section{Context Components}

\section{RESEARCH RESULT}

The results of the context evaluation, related to the implementation of the health insurance health care program by the family physician consisting of: (1) objective aspect, legal basis, regulations (ministerial and ministerial decrees) and health insurance protection counseling program, (2) participants of social health insurance, (3) guidance on the implementation of health care social health insurance program. Purpose, the legal basis. Implementation of health care social health insurance program. The process of conducting this research, the researcher evaluates the program of health service policy of social health insurance using documentation study by studying the applicable laws and regulations. Based on Law No. 40 of 2004 on the national social security system in Article 10 point 1 states that health insurance is held nationally based on the principle of social insurance and the principle of aquality. Furthermore, based on the provisions of Law No. 19 of 2003 on state-owned enterprises in article 66 paragraph 1 states that the Government may perform special assignment to state-owned enterprises to perform functions of public utility while maintaining the purpose and objectives of the activities of state-owned enterprises. This is consistent and consistent with the desired objectives in the implementation of the program, namely as an effort to ensure and improve the health status of public / health insurance participants in the city of Pontianak.

\section{Input components}

Evaluation of inputs related to the readiness of the program is the availability of available resources to achieve program objectives that have been established in the success of the preparation of a decision, to achieve the success of the program then is determined by the existing resources and strategies and steps that can be taken in the implementation of the program . (1) Recruitment of Health Insurance Participation, that the number of participants of Social Health Insurance in the family doctor's health care program is 10,478 inhabitants. After the participant of this social health insurance program is given the health insurance participant card according to the number of dependents, that is husband or wife and 2 (two) children, the family health insurance participant's card is used during the health service process by matching the document number of each participant card the insured. The participant card is only for participants according to the participant's document number and is not included in the insured list. Process on service in accordance with the guidance of implementation guidance. (2) Family health care facilities and infrastructure, as many as 6 outpatient primary care providers. The development of health services of family doctors, so that participants are able to access health services and affordable, in addition to the participants in order to feel the benefits psychologically in consult in a familial so that in accordance with the guidelines of the operational guidelines of Limited Company of Health insurance that all health providers of family physician programs Health insurance must perform health services in the plenary of health service promotive, preventive, curative and rehabilitative to all participants Health insurance. (3) Family physician resources. As a health care provider of family doctors in Pontianak City as many as 6 people spread from each residential area of health insurance participants in South Pontianak District (2 family doctors), Pontianak Southeast District, West Pontianak Subdistrict, East Pontianak Subdistrict, Pontianak Sub- City. (4) Financing. on the financing aspect which covers the financing capitation of health insurance participant served by the family doctor in accordance with the guidance of the implementation of Limited Company of Health Insurance. Funds for health insurance participants of family physicians based on the number of participants capitation served by family doctors amounted 
to 6,500 rupiah/ soul/ participants. Furthermore, the disbursement of capitation funds is paid by PT. Health insurance Pontianak City through the account of each family doctor.

\section{Process Components}

Implementation of the evaluation process aims to see the implementation of inputs that are applied in the form of implementation practices activities that lead to the implementation of programs aimed at improving public health services through health insurance coverage served by family doctors, related to standards / procedures health services health insurance social medical programs First Level Outpatient families, which are described through the evaluation of the process below. Procedure health care health insurance program family physician. Family doctor is a health care provider at the primary level of Outpatient Level. Whereas the rights of participants of the doctoral program are to obtain health services such as (1) promotion (health education / healthy lifestyle), (2) preventive (prevention of disease), (3) curative (disease treatment), (4) rehabilitative (the healing process of disease). Healthcare participant health insurance procedure is by showing the participant card, it is aimed to know the number of health insurance participant as registration requirement of visit at family health care provider. In the health services of family doctors more conducting curative services (disease treatment) and less to provide promotive, preventive and rehabilitative services, participants visit more desire to cure his illness.

\section{Product Components}

The level of satisfaction of the health insurance participants to the family doctor program shows that the providers of health services as many as 118 respondents (66\%) stated easy, while 62 respondents $(34 \%)$.

Level of health service requirements with type of family physician service shows that 145 respondents $(81 \%)$ stated appropriate and 29 respondents (16\%) very suitable service requirements with type of health services provided by family doctor, only 6 respondents (3\%) stating corresponding.

At the level of clarity the family doctor who served showed that the clarity of family doctors who perform health services as many as 143 respondents (79\%) stated clearly and 16 respondents (9\%) stated very clear, while 21 respondents (12\%) answered less clear.

At the level of discipline of family doctors at the time of carrying out health services above describes the discipline of family doctors in performing services to health insurance participants. The average respondent stated good in terms of discipline of the family doctor's service. family doctor's health service is opened in the afternoon in at 15:00 to 21:00 so that health insurance participants can be directly served well. As many as 114 respondents (63\%) stated discipline and 38 respondents (21\%) stated very discipline, but as many as 28 respondents (16\%) stated still less discipline.

At the level of responsibility of family doctors in carrying out health services there are 169 respondents (94\%) claimed to be satisfied with the responsibilities given by the family doctor. But on the contrary there are 11 respondents $(6 \%)$ admitted less satisfied with the responsibility of family doctors in carrying out health services.

At the level of the ability of family doctors in carrying out health services, shows about the background of the competence of a family doctor in the process of carrying out health services to health insurance patients. A total of 124 respondents (69\%) said they were able to carry out health services and 45 respondents (25\%) said they were very capable, but 11 respondents (6\%) said they were less able. This is because there are family doctors who are elderly but still implement health care programs for health insurance participants.

At the rate of speed in the process of health care family doctors showed that as many as 101 respondents $(56 \%)$ stated the family doctor quickly in carrying out health services on health insurance patients and 33 respondents (18\%) stated very quickly, so the patient family health insurance doctors 
do not take time a long time to visit the family doctor's health service, while 46 respondents (26\%) admitted the family doctor less quickly in carrying out health services.

At the level of Courtesy and Hospitality family doctors in health services showed that as many as 113 respondents $(63 \%)$ stated family doctors are polite and friendly in carrying out health services to health insurance participants and 61 respondents (34\%) said family doctors are very polite and friendly, there are 6 respondents (3\%) who stated family doctors were not polite and friendly.

At the level of fairness of financing in health services family doctors showed as many as 152 respondents (84\%) expressed satisfaction with the cost set in the health care family doctors and 28 respondents (16\%) expressed less satisfied with the cost set in the health service family, this is because the entire cost of health insurance patients of this program directly paid capitation by Limited Liability Insurance company.

At the healthcare cost equilibrium level with the costs set by Limited Company of Health Insurance shows that 155 respondents (86\%) stated the appropriate health care health insurance family physician with the cost set by Limited Health Insurance Company and 25 respondents (14\%) stated has been appropriate. This is because the entire patient's health insurance program is less aware of the cost of health services this family doctor.

At the level of Timeliness of health service schedule of family doctors showed that as many as 131 respondents $(73 \%)$ stated on time family doctors in carrying out health services and 49 respondents $(27 \%)$ stated very timely family doctors in carrying out health care health services, in the afternoon in at 15:00 to 21:00 pm.

At the comfort level of the family health service, the family doctor stated that as many as 137 respondents $(76 \%)$ stated that they feel comfortable to the family health service. Family doctors 37 respondents $(21 \%)$ stated very comfortable to the family doctor's health service, but 6 respondents (3\%) answered less comfortable.

At the health level of family health service, family physician showed that 146 respondents $(81 \%)$ stated that they were comfortable with the family health care environment and 34 respondents (19\%) stated that they were very comfortable with family health care.

At the level of conformity of health promotion service of family doctors showed that as many as 43 respondents (24\%) stated appropriate to health promotion services and as many as 7 respondents (4\%) stated very appropriate. But otherwise as many as 130 respondents (72\%) stated less appropriate because family doctors less to give counseling about healthy lifestyle.

In the appropriateness of preventive health services, family doctors showed that as many as 52 respondents (29\%) stated appropriate preventive health service by family physician and vice versa 128 respondents (71\%) stated family doctors lacking health service in preventive field is important because disease prevention process is effort the initial application for the community to conduct clean and healthy living behavior.

At the level of Compatibility of curative health care family doctors showed that 180 respondents $(100 \%)$ stated appropriate. This is because the health insurance patient's visit is only to treat the illness.

At the level of conformity of rehabilitative health services, family physicians indicated that only 78 respondents $(43 \%)$ stated appropriate to rehabilitative health services of family doctors to health insurance participants and vice versa 102 respondents (57\%) stated less appropriate. This is because the medical rehab service process is more in advanced health services in hospitals, but family doctors can provide medical rehab through counseling the healing process in every health insurance patient who visits the health service of the family doctor's program

\section{Description of Public Health Degree In Pontianak City}

The evaluation process on the components of the product includes the indicator of the success of public health service so that it will improve the public health status in Pontianak City and increase 
the achievement of clean and healthy life behavior program, decreasing maternal mortality rate and infant mortality rate and decreasing morbidity rate. Furthermore, the process of achieving the success of health insurance program health insurance policy by this family doctor can also be evaluated on new policies during the course of this program, namely:

\begin{tabular}{|c|l|c|c|c|}
\hline \multirow{2}{*}{ No. } & \multicolumn{1}{|c|}{ Indicator } & \multicolumn{3}{|c|}{ Results of program / year achievement } \\
\cline { 3 - 5 } & \multicolumn{2}{|c|}{$\mathbf{2 0 1 0}$} & $\mathbf{2 0 1 1}$ & $\mathbf{2 0 1 2}$ \\
\hline 1 & $\begin{array}{l}\text { Clean and healthy living } \\
\text { behavior of the household }\end{array}$ & $35,53 \%$ & $36,07 \%$ & $38,24 \%$ \\
\hline 2 & Maternal mortality rate & $98,8 \%$ & $98,3 \%$ & $97,6 \%$ \\
\hline 3 & Infant mortality rate & $2,5 \%$ & $11,3 \%$ & $3,95 \%$ \\
\hline 4 & Mortality rate & $252 \%$ & $179 \%$ & $167 \%$ \\
\hline
\end{tabular}

Source: Pontianak City Health Office Profile 2013

\section{DISCUSSION}

\section{Context Evaluation}

The purpose of this family doctor's health service program policy is very clear and is appropriate to ensure public health and the improvement of public health status (social health insurance participants) and with clear legal basis under the 1945 Constitution, article 34 paragraph 2, Act number 402004 concerning the National Social Security System and Act No. 36 of 2009 on health so that the legal basis and implementation process must be implemented for all institutions appointed as implementers of the intended program.

The Ministry of Health of the Republic of Indonesia has established a strategic plan (20102014) in the achievement of development programs in the health sector, such as efforts to increase the budget of health development in the aspect of national social health insurance by stipulating the program of health care guarantee program on the aspect of service quality, budget and accountability, as well as the arrangement and provision of health human resources equally and competence in accordance with the standards. In accordance with the opinion of Charles Purmand, basically this concept integrates the concept of delivery of care and financing of healthcare into a system to ensure the implementation of quality health services at an optimal cost. Based on the findings on the evaluation of the context in accordance with the aspects of (1) the purpose of program implementation, (2) and the implementation instructions of the program of the social health insurance participant of the family physician, (3) the implementation of the feasibility and the benefit of the evaluation program in the medium category. Furthermore, based on the findings, on the aspect of the context that needs to be attention and improvement is on aspects of program supervision and socialization of health insurance membership rights to health care of family doctors. Based on the findings, most family doctors have not conducted first-line outpatient services in a plenary manner such as promotive, preventive and rehabilitative services so that family doctors tend to do more curative services (disease treatment) in addition, many health insurance participants who do not know about the rights and health care benefits of family doctors, health insurance participants only know that using the card can be served for free treatment, whereas every civil servant / health insurance participant must be deducted by monthly salary and family. This is due to lack of information and socialization to the participants of the health insurance.

\section{Input Evaluation}

Based on the evaluation findings on the input components related to the utilization of available resources of human resources and program financing with the results of moderate actualization, the availability of drug laboratories, waiting room with the explanation that based on 
observations about the availability of health care facilities family doctors have been adequate but in implementing health services of health insurance participants are very few who provide facilities such as promotive instruments, preventive and even rehabilitative instruments are not owned at all. This is very important in an effort to improve education and knowledge of community / health insurance participants about healthy lifestyle in everyday life both personal and family. Therefore, Limited Liability Insurance Company of branch of Pontianak needs to do monitoring and supervision with related institution especially in coordination effort, information, synchronization and control of health service by family doctor. So that good governance performance that is with good governance principle will be realized by through service system in an integrated and commitment.

\section{Process Evaluation}

Evaluation results on process components that include (1) Participation service, (2) implementation of health service program, (3) fairness in utilization of cost with result of actualization of medium. from the 3 elements that are evaluated there are some things that need special attention. In the process of membership service, almost all participants, know about their rights in standardized doctors health care program in the guideline of the implementation guidance, so in this case Limited Company of Insurance has not maximally disseminated the matter to the family health insurance participant . Implementation of the policy of the family doctor health service program is actualized in the medium category, this is because according to the standard guideline of the implementation of health care program of family health insurance of doctors. In the process of health service efforts are not complete in the family doctors in providing health services more prioritize efforts curative service.

\section{Product Evaluation}

Through the health care program the health insurance participant of the family doctor is expected to contribute in the form of efforts to improve the degree of health that can be measured through 3 important indicators in the achievement of the Millennium Development Goals, namely households / households implementing clean and healthy living behavior, decreasing maternal mortality and mortality rate babies, decreased morbidity, description of the development of public health status of Pontianak City can be seen from time to time, but also an indicator of success in the assessment of health services and health development programs. In 2010 the family / households have implemented a clean and healthy life behavior amounted to $35.53 \%$ maternal mortality rate of 99.7 per 100,000 life. The infant mortality rate is 2.5 per 1,000 live births. The morbidity rate is $252 \%$. Healthcare program of health insurance participant of family doctor is said to be better if there is improvement of health degree. This can be seen in the year 2011 the behavior of clean and healthy life 36.07 , maternal mortality $99.4 \%$, infant mortality $11.3 \%$ the morbidity rate $179 \%$. Based on these data can be seen that the implementation of family health care program in Pontianak City, there is a tendency of public health status has increased. All of the participants are very hopeful that this family doctor's health service program is continued and developed, it is because it gives more convenience and smoothness in the process of health service, in terms of time and opportunity and fairness, in the future so that it can be further enhanced towards the national social insurance system that is insurance healthcare to be a Social Health Insurance Provider Body in accordance with the needs of the community.

\section{CONCLUSION}

Based on the formulation of the problem, objectives, findings and discussion in the previous chapter, it can be concluded as follows: Component Context on Implementation of health services, health insurance, family doctors, is in accordance with the aim of to ensure public health, especially the participants and his family. 
Input Component, Evaluation on standard procedure of health program implementation of community health insurance by family doctor on participant aspect, facilities and infrastructure and financing of energy resources have been in accordance with standard and making implementation instruction. But still needs to be socialized about the rights of the family health insurance participant. The availability of facilities and infrastructure and energy resources has been in accordance with the competence in performing health services of health insurance participants. Financing, in accordance with the prevailing provisions of the capitation payment system is also the health care of family doctors so that the cost of health care for family doctors is appropriate and reasonable for the financing of the first outpatient health service. In the process component of health service standard set the family health insurance program is implemented comprehensively according to the guidance of the implementation guidance, but still needs to be improved especially on health promotion, preventive and rehabilitative aspects. Product component (outcome) on evaluation of policy implementation of health insurance program of health insurance of family physician, public response is very positive and good and for family doctor health service program continuously implemented consistently and continuously because it can give protection and easiness in health service area and can increase degree of public health in the city of Pontianak.

\section{REFERENCE}

Anonymous. (2010). "Health Policy. http://kebijakan-kesehatanindonesia.net/?q=node/122/

Azrul Azwar. (1996). Introduction to Health Administration. Jakarta: Binarupa Aksara.

Danim Sudarwan. (2005). Introduction to Policy Research Studies. Jakarta: Bumi Aksara.

Depkes RI. (2006). Family Doctor Service Development Policy As A Qualified and Efficient Service. Directorate of Primary Medical Services Ministry of health republic Indonesia.

Irawan. H. (2008). 10 Principles of Customer Satisfaction. Jakarta: PT. Elex Media Komputindo.

Karyati, M. Mukti, AG. Nusyirwan, MS. (2004). Level Of Family Doctor's Satisfaction On Limited Capitation Payment System Health Insurance In Medan City. Journal of Health Services Management. Vol.07. No.02.

Kusumanegara, Solehuddin. (2010). Models and Actors in the Public Policy Process. Yogyakarta: Grafamedia.

Health Profile Pontianak City Pontianak Health Office. (2012).

A Limited Liability Company Indonesia Health Insurance. (2003). Guidelines for Outpatient Services Tk.I By Family Doctor For Social Askes Participants.

Sugianto Sutopo. (2001). Public Policy Analysis. Jakarta: Institute of State Administration.

Law No. 36 of 2009. About health. Surabaya: Ariloka Publisher.

Law No. 22 of 1999. About Local Government. Publisher Binarupa Aksara.

Law No. 25 of 1999. About Financial Balance of Central and Regional. Publisher Binarupa Aksara.

Wijono, Djoko. (1999). Quality Management of Health Services. Surabaya: Airlangga University Press. 